\title{
Experimental Study On The Identification Model Of Dynamic Milling Force Coefficient
}

\author{
Xinghua Niu ${ }^{1,2, a}$, Tianding Wang ${ }^{1,2, b}$, Tiemin Zhao ${ }^{1,2}$ and Qianyou Huang ${ }^{1,2}$ \\ ${ }^{1}$ Tianjin University of Technology, Tianjin 300384, China; \\ 2 Tianjin Key Laboratory of the Design and Intelligent Control of the Advanced Mechatronical System, \\ Tianjin 300384, China. \\ aniu_x_h@126.com, ${ }^{b}$ xiaocawtd2007@163.com
}

Keywords: milling force model, coefficient identification, orthogonal experiment, regression analysis.

\begin{abstract}
The identification model of milling force coefficient is established using the model of dynamic milling force and the regression analysis of the milling force experiment data. On the basis of the existing milling force model, by simplifying and calculation, it can get the relational expression between milling force coefficient and average value of the milling force. Arranging the milling force experiment and measuring average milling force, the experiment results of milling force coefficient can be calculated. Then, the polynomial expression of identification model of milling force coefficient is established, and its coefficient values can be got by regression analysis. Finally, the accuracy and applicability of the identification model is verified by experiment. The experimental results show that the prediction results of the model are accurate and reliable, and can meet different processing conditions, provide the theoretical basis and reference for the further study of milling process and optimization.
\end{abstract}

\section{Introduction}

In the process of metal cutting, the cutting force has a great influence on the machining quality and efficiency. Mechanical model of cutting force is put forward by Sabberwaal[1] firstly, witch makes an assumption that the direct proportional for cutting force and the cross-sectional area of chip, and the proportion coefficient depends on the cutting condition and material properties. With the continuous development of machining technology, the cutting force model is improved constantly, and be used in milling. There are many scholars who study on cutting force model and the dynamic cutting process, and put forward a lot of cutting force model under different conditions [2,3,4]. Different cutting force model can be seen theoretically as a function of cutting parameters, cutting condition and the cutting force coefficient [5]. According to different approaches, the coefficient of cutting force has different models, such as: average cutting force coefficient model, bi-linear force model, exponential chip thickness model, semi-mechanic model, high order force model, etc [6]. Coefficient of cutting force can be obtained by the test method, witch has two kinds basically, one method can obtained the bevel milling cutting force coefficient through orthogonal cutting database, and another method is a mechanics method that can fast calibrate the coefficient of oblique cutting force $[7,8]$.

\section{Identification arithmetic of milling force coefficient}

Knowing number of teeth of milling cutter is $\mathrm{N}$, helical angle is $\beta$, radius is $\mathrm{R}$, cutting in axial direction is $\mathrm{a}_{p}$, cutting in radial direction is $a_{e}$. The milling cutter is divided to $\mathrm{M}$ elements in axial direction.

Through coordinate transformation, by integral operation, the instantaneous cutting force in tangential, radial and axial direction can be rewritten as follows 


$$
\left\{\begin{array}{l}
F_{x}=\sum_{j=1}^{N} \sum_{l=1}^{M}\left[-d F_{t j l} \cos \phi_{j l}-d F_{r j l} \sin \phi_{j l}\right] \\
F_{y}=\sum_{j=1}^{N} \sum_{l=1}^{M}\left[d F_{t j l} \sin \phi_{j l}-d F_{r j l} \cos \phi_{j l}\right] \\
F_{z}=\sum_{j=1}^{N} \sum_{l=1}^{M}\left[d F_{a j l}\right]
\end{array}\right.
$$

Where $\phi_{j l}$ is the instantaneous radial contact angle at teeth $\mathrm{j}$ and element $l, d F_{t j l}, d F_{r j l}, d F_{a j l}$ is respectively the force element on the cutter tooth $\mathrm{j}$, thickness $\mathrm{d}_{z}$ and cutting edge $l$ in tangential, radial and axial direction

In the process of milling, the cutting edge works in effective contact interval $\phi_{s t} \leq \phi_{j} \leq \phi_{e x}$, the instantaneous cutting force is integrated in a period of principal axis, and the results calculated by dividing the tooth-spacing angle, so the average cutting force in a period can be got for each tooth. This paper only study on milling force coefficient in tangential and radial direction, so only considering the milling force in $\mathrm{X}$ and $\mathrm{Y}$ direction. In the case of no spiral Angle and straight tooth cutting, by integral operation, the average cutting force can be written as follows.

$$
\left\{\begin{array}{l}
\bar{F}_{x}=\left\{\frac{N a_{P} f_{t}}{8 \pi}\left[K_{t c} \cos 2 \phi+K_{r c}(2 \phi+\sin 2 \phi)\right]\right\}_{\phi_{s t}}^{\phi_{e x}} \\
\bar{F}_{y}=\left\{\frac{N a_{P} f_{t}}{8 \pi}\left[K_{t c}(2 \phi+\sin 2 \phi)-K_{r c} \cos 2 \phi\right]\right\}_{\phi_{s t}}^{\phi_{e x}}
\end{array}\right.
$$

In this paper, with the milling cutter witch has straight tooth and no eccentricity for milling experiments, the entry angle is $\phi_{s t}=\arcsin \frac{R-a_{e}}{R}$, and exit angle is $\phi_{e x}=\frac{\pi}{2}$, so (9) can be rewritten as

$$
\left\{\begin{array}{l}
\bar{F}_{x}=-\frac{N a_{P} f_{t}}{8 \pi}\left(1+\cos 2 \phi_{s t}\right) K_{t c}+\frac{N a_{P} f_{t}}{8 \pi}\left(\pi-2 \phi_{s t}-\sin 2 \phi_{s t}\right) K_{r c} \\
\bar{F}_{x}=\frac{N a_{P} f_{t}}{8 \pi}\left(\pi-2 \phi_{s t}-\sin 2 \phi_{s t}\right) K_{t c}+\frac{N a_{P} f_{t}}{8 \pi}\left(1+\cos 2 \phi_{s t}\right) K_{r c}
\end{array}\right.
$$

\section{The milling force experiment}

\subsection{The experimental and results.}

The experimental conditions as follows. The machine tool is four axis linkage vertical machining center YCM-V65A, the Milling dynamometer is YDX-III9702. The material of test piece is 45 \# steel. Cutter teeth are 4, cutter diameter is $22 \mathrm{~mm}$, cutter materials for high speed steel, and cutter Angle is $30^{\circ}$. Cutting conditions is climb and dry milling. Experiment principle and the experiment scene as shown in figure 1 .

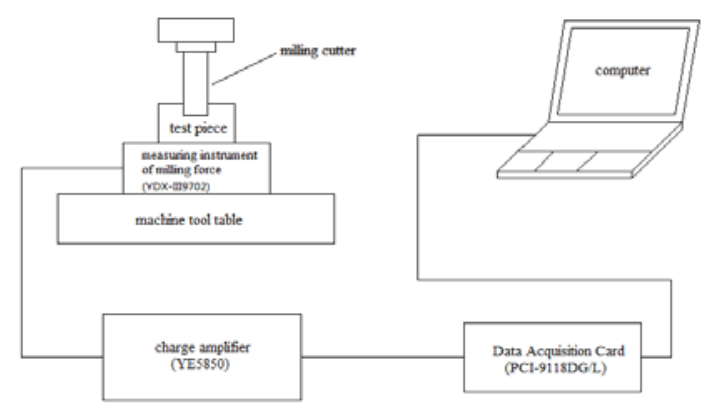

(a) Measuring principle

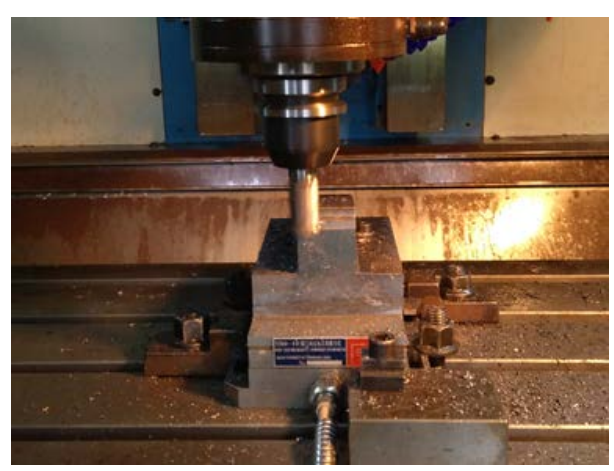

(b) Measuring scene

Fig. 1 Measuring principle and measuring scene 
This experiment is arranged based on orthogonal table $L_{9}\left(3^{4}\right)$, and the experimental results as shown in table 1.

Table 1 Experimental arrangement for milling force

\begin{tabular}{ccccccccc}
\hline $\begin{array}{c}\text { test } \\
\text { number }\end{array}$ & $\begin{array}{c}n / \\
(r / \mathrm{min})\end{array}$ & $\begin{array}{c}f_{t} / \\
(\mathrm{mm} / \mathrm{z})\end{array}$ & $\begin{array}{c}a_{p} / \\
\mathrm{mm}\end{array}$ & $\begin{array}{c}a_{e} / \\
m m\end{array}$ & $\bar{F}_{x} / N$ & $\bar{F}_{y} / N$ & $\begin{array}{c}K_{t c} / \\
\left(N / \mathrm{mm}^{2}\right)\end{array}$ & $\begin{array}{c}K_{r c} / \\
\left(N / \mathrm{mm}^{2}\right)\end{array}$ \\
\hline $1-1$ & 600 & 0.016 & 4 & 0.12 & -13.83 & 21.12 & 17022 & 19285 \\
$1-2$ & 600 & 0.022 & 5 & 0.16 & -19.57 & 31.70 & 11204 & 12650 \\
$1-3$ & 600 & 0.028 & 6 & 0.20 & -24.63 & 41.48 & 7436 & 8039 \\
$1-4$ & 700 & 0.016 & 5 & 0.20 & -22.20 & 34.96 & 13650 & 14699 \\
$1-5$ & 700 & 0.022 & 6 & 0.12 & -22.34 & 39.09 & 13789 & 17533 \\
$1-6$ & 700 & 0.028 & 4 & 0.16 & -17.21 & 25.79 & 9374 & 9801 \\
$1-7$ & 800 & 0.016 & 6 & 0.16 & -24.75 & 43.21 & 15845 & 18757 \\
$1-8$ & 800 & 0.022 & 4 & 0.20 & -19.05 & 28.65 & 10735 & 11283 \\
$1-9$ & 800 & 0.028 & 5 & 0.12 & -20.29 & 33.05 & 11804 & 13745 \\
\hline
\end{tabular}

\subsection{Identification model of milling force coefficient.}

Accoding to the references [9], the identification model of the dynamic milling force coefficient, can be written as

$$
\left\{\begin{array}{l}
K_{t c}=a_{0}+a_{1} a_{P}+a_{2} f_{t}+a_{3} a_{e}+a_{4} a_{P}^{2}+a_{5} f_{t}^{2}+a_{6} a_{e}^{2} \\
+a_{7} a_{P} n+a_{8} a_{P} f_{t}+a_{9} a_{P} a_{e}+a_{10} f_{t} a_{e} \\
K_{r c}=b_{0}+b_{1} a_{P}+b_{2} f_{t}+b_{3} a_{e}+b_{4} a_{P}^{2}+b_{5} f_{t}^{2}+b_{6} a_{e}^{2} \\
+b_{7} a_{P} n+b_{8} a_{P} f_{t}+b_{9} a_{P} a_{e}+b_{10} f_{t} a_{e}
\end{array}\right.
$$

Where $a_{0}, a_{1}, \cdots, a_{10}, b_{0}, b_{1}, \cdots, b_{10}$ is regression coefficient.

MATLAB software is used to make least squares regression analysis [10], result the regression coefficient for the identification model of milling force coefficient, its value as shown in table 2 .

Table 2 value of regression coefficient

\begin{tabular}{cccc}
\hline $\begin{array}{c}\text { regression } \\
\text { coefficient }\end{array}$ & value & $\begin{array}{c}\text { regression } \\
\text { coefficient }\end{array}$ & value \\
\hline$a_{0}$ & 50101.2106 & $b_{0}$ & 47995.7136 \\
$a_{1}$ & -3408.5842 & $b_{1}$ & 958.1191 \\
$a_{2}$ & -1105254.3287 & $b_{2}$ & -1603279.2422 \\
$a_{3}$ & -129648.4762 & $b_{3}$ & -149736.1128 \\
$a_{4}$ & 260.5664 & $b_{4}$ & 4.9877 \\
$a_{5}$ & 14975062.8076 & $b_{5}$ & 17002187.0256 \\
$a_{6}$ & 240426.2705 & $b_{6}$ & 209832.1165 \\
$a_{7}$ & 1.0487 & $b_{7}$ & 1.6711 \\
$a_{8}$ & -9583.2151 & $b_{8}$ & -12983.8779 \\
$a_{9}$ & 2504.8629 & $b_{9}$ & -6024.6818 \\
$a_{10}$ & -179665.3382 & $b_{10}$ & 1992548.7064 \\
\hline
\end{tabular}

To verify the accuracy and practicability of the milling force coefficient model, additional milling force experiments are arranged, then comparing the experiment value $\left(\bar{F}_{x} 、 \bar{F}_{y}\right)$ and the predicted value $\left(\bar{F}_{x}^{\prime} 、 \bar{F}_{y}^{\prime}\right)$ of milling force. Experimental conditions as stated in section 3.1, the experimental arrangement and the results as shown in table 3. 
Table 3 Experimental arrangement for model verification

\begin{tabular}{ccccccccc}
\hline $\begin{array}{c}\text { test } \\
\text { number }\end{array}$ & $\begin{array}{c}n / \\
(r / \min )\end{array}$ & $\begin{array}{c}f_{t} / \\
(\mathrm{mm} / \mathrm{z})\end{array}$ & $\begin{array}{c}a_{P} / \\
m m\end{array}$ & $\begin{array}{c}a_{e} / \\
m m\end{array}$ & $\bar{F}_{x} / N$ & $\bar{F}_{x}^{\prime} / N$ & $\bar{F}_{y} / N$ & $\bar{F}_{y}^{\prime} / N$ \\
\hline $2-1$ & 500 & 0.012 & 3 & 0.08 & -7.41 & -7.57 & 10.14 & 10.5 \\
$2-2$ & 550 & 0.014 & 3.5 & 0.10 & -10.36 & -10.74 & 15.05 & 15.71 \\
$2-3$ & 650 & 0.018 & 4.5 & 0.14 & -16.66 & -17.4 & 27.30 & 27.98 \\
$2-4$ & 750 & 0.026 & 5.5 & 0.18 & -24.11 & -24.44 & 41.97 & 42.55 \\
$2-5$ & 850 & 0.030 & 6.5 & 0.22 & -34.26 & -35.7 & 62.41 & 63.24 \\
$2-6$ & 900 & 0.032 & 7 & 0.24 & -32.95 & -33.31 & 59.21 & 62.83 \\
\hline
\end{tabular}

Seeing from table 3 , the experimental value and the calculated value of average milling force in $\mathrm{X}$ and $\mathrm{Y}$ direction is relatively close, it can be calculated that the maximum error respectively is $4.25 \%$ and $5.76 \%$, the average error respectively is $2.73 \%$ and $3.08 \%$, so the model this paper has established has higher accuracy and better applicability for predicting the milling force.

\section{Summary}

This paper presents the relational expression between milling force coefficient and average value of the milling force by simplification and calculation based on the existing dynamic milling force model. Through the regression analysis, the identification model of milling force coefficient is established using the experimental data. The experimental verification results show that the experimental value and the calculated value of average milling force is relatively close, so the model this paper has established has higher accuracy and better applicability. The research results can be used in the milling process simulation and other related problems, and provide the theoretical basis and reference for further study and optimization of milling force model.

\section{References}

[1]. Sabberwaal A J. Chip section and cutting force the milling operation. Annals of the CIRP.Vol.10(1961)No.3,p.197-203.

[2]. Lee P, Altintas Y. Predication of ball-end milling forces from orthogonal cutting data. International Journal of Machine Tools and Manufacture.Vol.36(1996)No.9,p.1059-1072.

[3]. Yun W S, Cho D W. Accurate 3-D cutting force prediction using cutting condition independent coefficients in end milling. International Journal o f Machine Tools \& Manufacture.Vol.41 (2001)No.4,p.463-478.

[4]. Yoon M C, Kim Y G. Cutting dynamic force modeling of end milling operation. Journal of Materials Processing Technology. (2004) p.155-156:1383-1389.

[5]. Koenigsberger F, Sabberwaal A J P. An investigation into the cutting force pulsations during milling operations. International Journal of Machine Tool Design and Research. (1961) p.1:15-33.

[6]. Liu Qiang, Li Zhongqun. Simulation and optimization of CNC milling process-modeling, algorithms and applications. Aviation Industry Press,2011.p.26-28.

[7]. Budak E , Altintas Y, Armarego E J A . Predication of milling force from orthogonal cutting data. ASM E Journal of Manufacturing Science and Engineering.Vol.118(1996)No.2,p.216-224.

[8]. Armarego E J A, Despande N P. Computerized end-milling force predication with cutting models allowing for eccentricity and cutter deflections. Annals of the CIRP.Vol.40(1991)No.1,p.25-29.

[9]. He Xiaoqun. Practical regression analysis. Higher Education Press,2008, p.43-55. 
[10]. Zhang Kun, Bi Jing, and Cong Bin. MATLAB 7.6 From the introduction to the master. Electronic Industry Press,2009, p.312-320. 